\title{
Mitochondria Targeted Peptide Attenuates Mitochondrial Dysfunction, Controls Inflammation and Protects Against Spinal Cord Injury-Induced Lung Injury
}

\author{
Liu-Long Zhu Mao-Qiang Li Fan He Shao-Bo Zhou Wu Jiang \\ Hangzhou First People's Hospital, Nanjing Medical University, Shangcheng District, Hangzhou, China
}

\section{Key Words}

Lung injury • Spinal cord injury • Mitochondrial dysfunction • Inflammation

\begin{abstract}
Background/Aims: Spinal cord injury (SCI) is a common and devastating disease, which results in systemic inflammatory response syndrome and secondary lung injury. Mitochondrial dysfunction and inflammation are closely related to lung injury in diverse disease models. No studies have demonstrated the effects of mitochondrial targeted peptide SS-31 in a mouse model of SCI-induced lung injury. Methods: Immediately after injury, mice in the treatment groups received a daily, single-dose intraperitoneal injection of SS-31 and for the next 2 days. The sham and SCI groups also received a daily single dose of vehicle (DMSO and $0.9 \% \mathrm{NaCl}, 1: 3$ ). The lung tissue of mice was examined after SCI, and tissue damage, apoptosis, inflammation, and mitochondrial dysfunction were recorded. Results: SS-31 treatment attenuated lung edema and tissue damage. Furthermore, SS-31 treatment reduced apoptosis of alveolar type II cells, the number of total macrophages and M1 macrophages, and neutrophil infiltration. Moreover, SS-31 treatment attenuated reactive oxygen species levels, reversed mitochondrial dysfunction and inhibited NLRP3 inflammasome activation. Conclusions: Collectively, our results demonstrate that SS-31 attenuates mitochondrial dysfunction, controls inflammatory responses, and alleviates the severity of lung damage in a mouse model of SCI-induced lung injury.

\section{Introduction}

Spinal cord injury (SCI) is a fatal neuro-destructive disease, with a variety of complications [1-3]. Pulmonary complications contribute significantly to the mortality and morbidity of SCI patients [2, 3]. Accumulating evidence indicates that SCI not only causes inflammation of spinal cord tissue, but also results in systemic inflammatory response 


\section{Cellular Physiology Cell Physiol Biochem 2017;44:388-400 \begin{tabular}{l|l|l}
\hline and BOI: 10.1159/000484919 & $\begin{array}{l}\text { C } 2017 \text { The Author(s). Published by S. Karger AG, Basel } \\
\text { www.karger.com/cpb }\end{array}$
\end{tabular} \\ Zhu et al.: SS-31 Attenuates Lung Injury}

syndrome (SIRS), which leads to multiple organ damage, most seriously in the lungs [4-8]. Secondary pulmonary damage after lower level SCI, such as thoracic cord injury, results in the formation of a susceptible environment for pulmonary infection, and contributes to an important pathological basis of pulmonary complications in the early stage $[9,10]$. Moreover, SCI-induced lung injury may induce life-threatening lung dysfunction $[4-6,9,10]$. Therefore, attenuating lung injury is vital for controlling pulmonary complications in SCI. However, SCIinduced lung injury lacks effective interventions $[9,10]$.

Mitochondria are the major source of reactive oxygen species (ROS) and contribute to cell signal transduction [11]. Mitochondrial dysfunction leads to increased ROS production, mitochondrial DNA damage (copy number reduction and mutation), and disorders of oxidative phosphorylation of the mitochondrial respiratory chain [12, 13]. Previous reports have shown mitochondrial dysfunction, which is important for energy metabolism, inflammatory responses, oxidative stress, the intrinsic apoptotic pathway, plays a substantial role in lung injury $[14,15]$. Moreover, mitochondrial DNA provokes systemic inflammation in lipopolysaccharide (LPS)-induced lung injury in rats [15]. Furthermore, mitochondrial DNA damage initiates lung injury and multi-organ system failure in rats following intratracheal Pseudomonas aeruginosa administration [16]. In addition, mitochondrial ROS are considered to be important factors in NOD-like receptor protein-3 (NLRP3) inflammasome activation [12]. Therefore, regulation of mitochondrial dysfunction is an important strategy for the treatment of SCI-induced lung injury.

SS-31, a new and innovative aromatic cationic peptide, selectively targets the mitochondrial inner membrane [17]. Furthermore, SS-31 can scavenge ROS [18]. In addition, SS-31 is efficacious in reversing mitochondrial dysfunction [17-19]. No studies have demonstrated the effects of SS-31 in a mouse model of SCI-induced lung injury. Hence, the aim of the present study was to test whether SS-31 could protect against lung injury following SCI in mice.

\section{Materials and Methods}

\section{Animals}

Animal experiments were conducted in female C57BL/6 mice (25-30 g). All animal procedures were approved by the Ethics Committee of Hangzhou First People's Hospital. Animals were maintained under controlled conditions with $12 \mathrm{~h}$ light/dark cycle, at $23^{\circ} \mathrm{C}$ and with access to food and water ad libitum.

\section{Surgical Procedure and Experimental Protocol}

Mice were anesthetized with ketamine $(75 \mathrm{mg} / \mathrm{kg})$ and xylazine $(3 \mathrm{mg} / \mathrm{kg})$ intraperitoneally. The muscles overlying the T5 to T8 vertebrae were dissected, followed by laminectomy to expose the spinal cord. To produce SCI, extradural compression of the spinal cord at the T6-T7 vertebral level was conducted via an aneurysm clip for $1 \mathrm{~min}$, as described by Paterniti et al [20].. The aneurysm clip had a closing force of $30 \mathrm{~g}$ based on a previous study [21]. Mice that underwent laminectomy alone served as the sham group. Immediately after injury, mice in the SCI + SS-31 group received a daily single-dose intraperitoneal injection of SS-31 (China Peptides Co. Ltd., Shanghai, China) at $5 \mathrm{mg} / \mathrm{kg}$ and for the next 2 days. The sham and SCI groups also received a daily single dose of vehicle (isotonic saline). Mice underwent manual bladder expression twice a day until recovery of reflex bladder emptying. Mice were deeply anesthetized, sacrificed and lung (left) samples were collected 3 days post-injury. The timing and dose of SS-31 were based on previous research with maximum protective effects and without evident toxicity $[19,22]$.

Measurement of lung edema

Lung samples were collected and cleared of extrapulmonary tissue. Subsequently, samples were weighed (wet weight), dried at $60^{\circ} \mathrm{C}$ for $48 \mathrm{~h}$, and weighed again (dry weight). The wet weight to dry weight was calculated to assess the degree of lung edema ( $\mathrm{n}=5$ mice/group). 


\section{Cellular Physiology Cell Physiol Biochem 2017;44:388-400 \begin{tabular}{l|l|l} 
and Biochemistry Published & DOI: 10.1159/000484919 & $\begin{array}{l}\text { C } 2017 \text { The Author(s). Published by S. Karger AG, Basel } \\
\text { www.karger.com/cpb }\end{array}$
\end{tabular} Zhu et al.: SS-31 Attenuates Lung Injury}

\section{Paraffin section preparation}

Lung tissue samples were dissected out after transcardial perfusion with cold physiological saline and $4 \%$ paraformaldehyde, fixed in paraformaldehyde at room temperature, dehydrated, and embedded in paraffin. Transverse paraffin sections ( $4 \mu \mathrm{m}$-thick) were used for hematoxylin and eosin staining, immunofluorescence labeling, and terminal dexynucleotidyl transferase-mediated dUTP nick end labeling (TUNEL).

\section{Histologic evaluation}

For histologic evaluation, paraffin-embedded sections $(4 \mu \mathrm{m})$ were stained with hematoxylin and eosin. Each histologic characteristic was graded from 0 (normal) to 5 (maximal) based on cell infiltration, alveolar wall thickening, congestion, intraalveolar hemorrhage, and edema by a pathologist who was blinded to the allocation of groups according to a previous study [23]. The histologic score from four optical fields in each of the five sections per animal were averaged ( $n=5$ mice/group).

\section{Immunofluorescence labeling}

After deparaffinization, the sections underwent microwave repair in $0.01 \mathrm{M}$ citrate buffer solution $(\mathrm{pH}=6.0)$, followed by incubation overnight with primary antibodies anti-myeloperoxidase (MPO) (1:500, Abcam, Cambridge, UK), anti-Iba-1 (1:500, Abcam), and anti-CD68 (1:300; Santa Cruz, CA, USA) combined with anti-inducible nitric oxide synthase (iNOS) (1:300; Santa Cruz) and subsequently incubated with appropriate secondary antibodies followed by nuclear staining with DAPI. Images were obtained with a fluorescence microscope (Olympus, Tokyo, Japan). Cell counts and analysis were performed using ImageJ software $(1.4, \mathrm{NIH})$. The number of positive cells from four optical fields (high power field, $225 \mu \mathrm{m} \times 162 \mu \mathrm{m}$ ) in each of the five sections per animal were averaged ( $\mathrm{n}=5$ mice/group).

\section{TUNEL}

TUNEL staining was performed using an In Situ Cell Death Detection kit (Roche, Basel, Switzerland) according to the manufacturer's instructions. Briefly, after deparaffinization, slides were incubated with proteinase-K, then TUNEL reaction mixture, followed by blocking buffer with peroxidase-streptavidin conjugate solution, and finally $0.03 \%$ diaminobenzidine. For co-staining of surfactant proteins, SP-C and TUNEL, the slices were first labeled with the anti-SP-C (1:300; Santa Cruz), and then TUNEL followed by nuclear staining with DAPI. Images were examined by a fluorescence microscope (Olympus, Tokyo, Japan). The number of positive cells from four optical fields (high power field, $450 \mu \mathrm{m} \times 325 \mu \mathrm{m}$ ) in each of the five sections per animal were averaged ( $\mathrm{n}=5$ mice/group).

\section{Extraction of fresh tissue}

Lung (left) tissue was dissected out after transcardial perfusion with cold physiologic saline, and subsequently carefully removed and stored at $-80^{\circ} \mathrm{C}$ until use for quantitative real-time PCR (qPCR), western blot and ROS detection.

\section{$q P C R$}

Total RNA and DNA was isolated using TRIzol reagent (Invitrogen, Carlsbad, CA, USA) and a DNeasy Tissue Kit (Qiagen, Valencia, CA, USA), respectively. All primers used were designed through Primer 3 software (Table 1). The mRNA expression levels of genes and mitochondrial (mt) DNA copy number was

Table 1. Real-time PCR primer sequences

\begin{tabular}{lcc}
\hline Gene & Forward primer $\left(5^{\prime}{ }^{\prime}-3^{\prime}\right)$ & Reverse primer $\left(5^{\prime}-3^{\prime}\right)$ \\
\hline iNOS & CGCTTGGGTCTTGTTCACT & TCTTTCAGGTCACTTTGGTA \\
GAPDH & TCATGGATGACCTTGGCCAG & GTCTTCACTACC ATGGAGAAGG \\
Mitochondrial DNA & TTTTATCTGCATCTGAGTTTAATCCTGT & CCACTTCATCTTACCATTTATTATCGC \\
ATP synthase & TCCATCAAAAACATCCAGAAAA & GAGGAGTGAATAGCACCACAAA \\
$18 \mathrm{~S}$ & TTCGGAACTGAGGCCATGATT & TTTCGCTCTGGTCCGTCTTG \\
\hline
\end{tabular}


detected. For qPCR of mRNA expression levels of genes and mtDNA copy number, reverse transcription was carried out, followed by real-time PCR amplification. The copy number of mtDNA expression and ATP synthase mRNA expression were normalized against the 18S rRNA (encoded by nuclear DNA) level; other mRNA expression levels were normalized against reference gene GAPDH and measured using the $\triangle \triangle \mathrm{CT}$ method ( $\mathrm{n}=5$ mice/group).

\section{ROS detection}

Lung tissue samples were cut into pieces and digested by pancreatic enzyme at $37^{\circ} \mathrm{C}$ for $1 \mathrm{~h}$, followed by filtration, centrifugation, and removal of the supernatant. 2, 7-Dichlorodi-hydrofluorescein diacetate (DCFH-DA) was added and incubation incubated for $20 \mathrm{~min}$ at $37^{\circ} \mathrm{C}$, followed by washing with serum free medium three times, and appropriate phosphate buffer saline (PBS)suspension. ROS level was detected by flow cytometry (FACSCalibur; BD Biosciences, San Diego, CA, USA) (n=5 mice/group).

\section{Western Blot}

For protein sample preparation, lung specimens were homogenized and extracted with RIPA buffer (Beyotime, Nanjing, China). Protein concentration was measured with a $\mathrm{BCA}^{\mathrm{TM}}$ protein assay kit (Pierce, Bonn, Germany) according to the manufacturer's instructions. Total protein (30 $\mu \mathrm{g} / \mathrm{lane})$ was separated through sodium dodecyl sulfate polyacrylamide gel electrophoresis, and then transferred to polyvinylidene difluoride membranes (Millipore, Bedford, MA, USA). Thereafter, membranes were blocked with 5\% skimmed milk, and then incubated with the following primary antibodies: anti-NLRP3, anti-caspase-1 (all 1:1000; Santa Cruz Biotechnology, Santa Cruz, CA, USA), anti-IL-1 $\beta$ (1:1000; Cell Signaling Technology, MA, USA), and $\beta$-actin (1:1000; Santa Cruz Biotechnology) overnight at $4^{\circ} \mathrm{C}$, followed by incubation with the respective secondary antibody. Moreover, the level of cytosolic cytochrome c (Cyt C) (1:1000; Abcam, Cambridge, UK) was also determined. For densitometric quantification, the specific band intensities were normalized to $\beta$-actin in the same blot ( $n=5$ mice/group).

\section{Statistical Analysis}

All values are presented as the mean \pm standard error of the mean (SEM). Statistical differences between groups were analyzed using one-way analysis of variance (ANOVA) followed by Tukey's posthoc test. When the values in the study were not normally distributed, statistical differences were analyzed using one-way ANOVA on ranks with post hoc Dunn's method. A P-value of less than 0.05 was considered statistically significant.

\section{Results}

\section{SS-31 alleviates lung edema}

Lung edema was analyzed by wet/dry weight ratio. SCI mice $(1.5 \pm 0.13, \mathrm{P}=0.009$, Fig. 1) had a higher ratio than sham mice (2.6 \pm 0.27 , Fig. 1$)$, indicating that SCI mice were significantly edematous $72 \mathrm{~h}$ postinjury. However, treatment with SS-31 significantly antagonized lung edema by reducing the wet /dry weight ratio (1.8 \pm $0.13, P=0.039$, Fig. 1), indicating that SS31 treatment significantly alleviates lung edema post-injury.

\section{SS-31 ameliorates histological injury}

To assess lung injury, lung sections were stained with hematoxylin and eosin (Fig. 2A-2C). As shown in Fig. 2B, substantial morphologic changes including

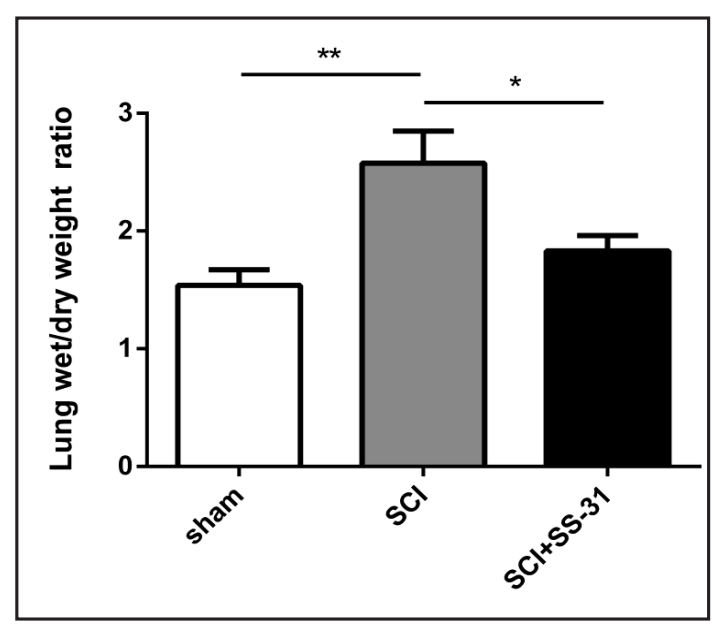

Fig. 1. SS-31 alleviates lung edema. Wet/dry weight ratio was used to estimate lung edema 3 days postinjury. ${ }^{*} \mathrm{P}<0.05,{ }^{* *} \mathrm{P}<0.01$. Data represent means \pm SEM, $\mathrm{n}=5$. 
Fig. 2. SS-31 ameliorates histological injury. (A-D) Hematoxylin and eosin staining was used to assess lung injury pathology 3 days post-injury. (A) Sham, (B) SCI, (C) SCI+SS-31. (D) Quantitative estimation of lung damage scores. $* * * \mathrm{P}<0.001$. Data represent means \pm SEM, $n=5$. Scale bars are $50 \mu \mathrm{m}$.

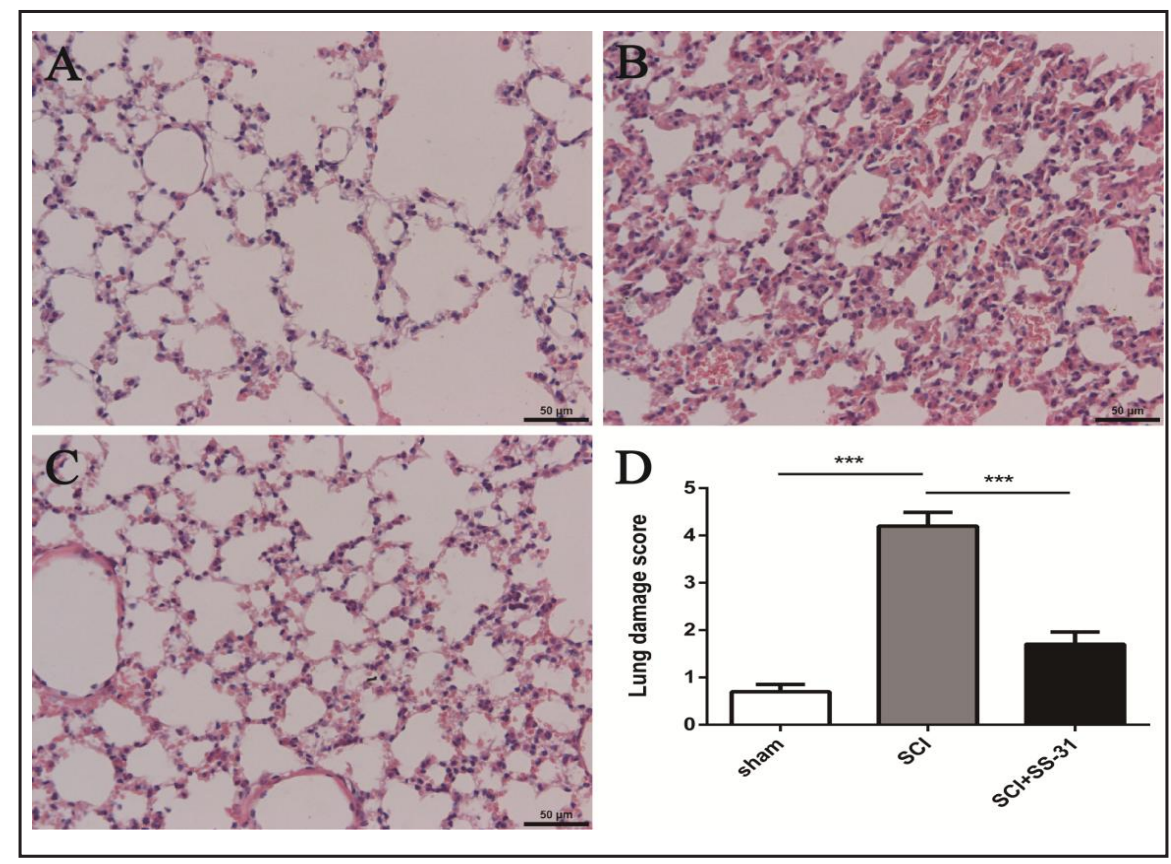

Fig. 3. SS-31 attenuates apoptosis of alveolar type II cells. (A) Costaining with SP-C (red fluorescence) and TUNEL (green fluorescence) was used to estimate the loss of alveolar type II cells 3 days post-injury. (B) Quantitative estimation of TUNEL-positive alveolar type II cells. HP, High power. $* * * \mathrm{P}<0.001$. Data represent means \pm SEM, $n=5$. Scale bars are $50 \mu \mathrm{m}$.

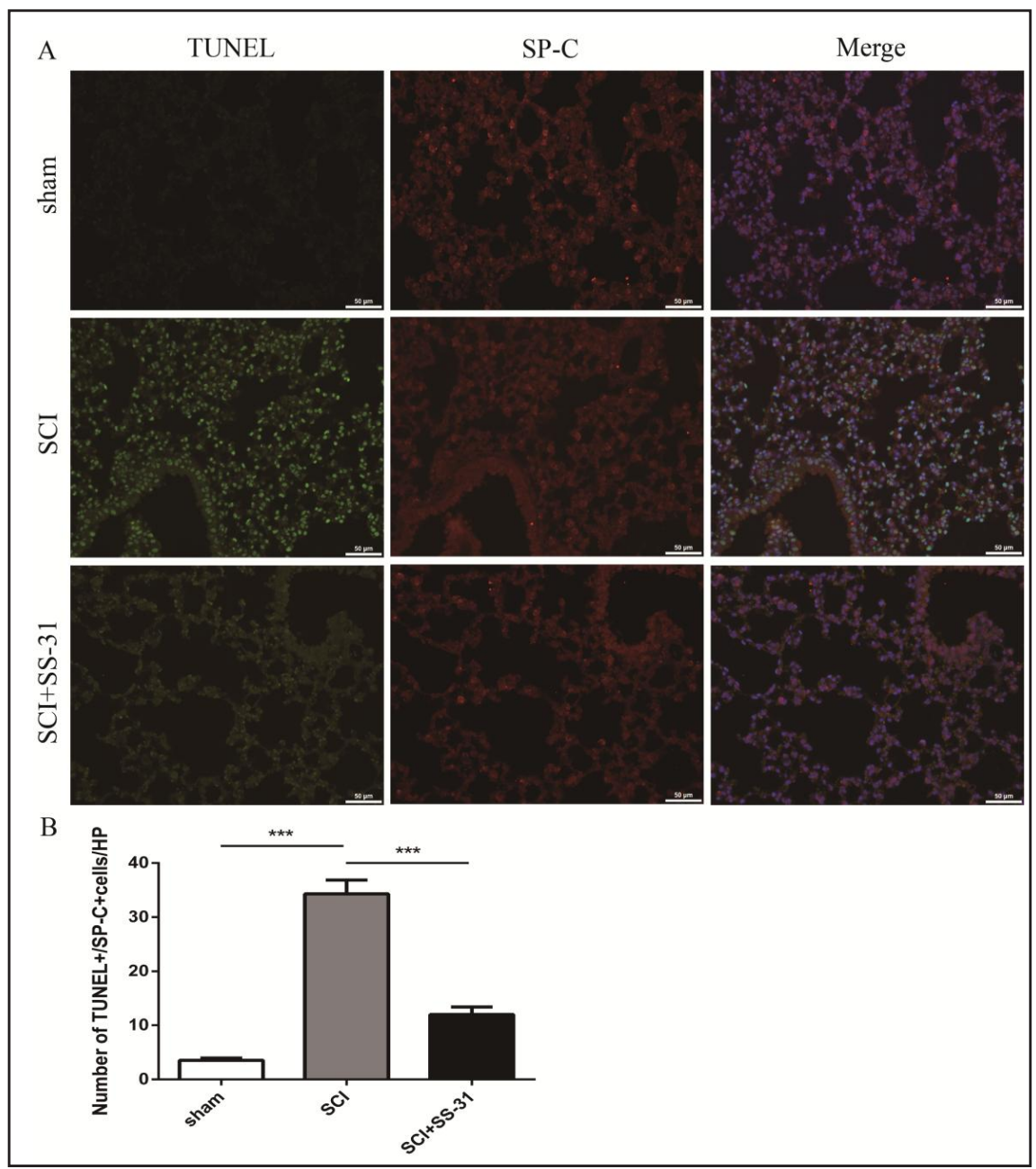


Fig. 4. SS-31 diminishes the number of neutrophils. (A-C) Im mun ofluores cence labeling was used to estimate the number of neutrophils 3 days after SCI. (A) Sham, (B) SCI, (C) SCI+SS-31. (D) Quantification analysis of MPOpositive (green fluorescence) cells. HP, High power. *P<0.05, $\quad * * \mathrm{P}<0.01$. Data represent means \pm SEM, $n=5$. Scale bars are 25 $\mu \mathrm{m}$.
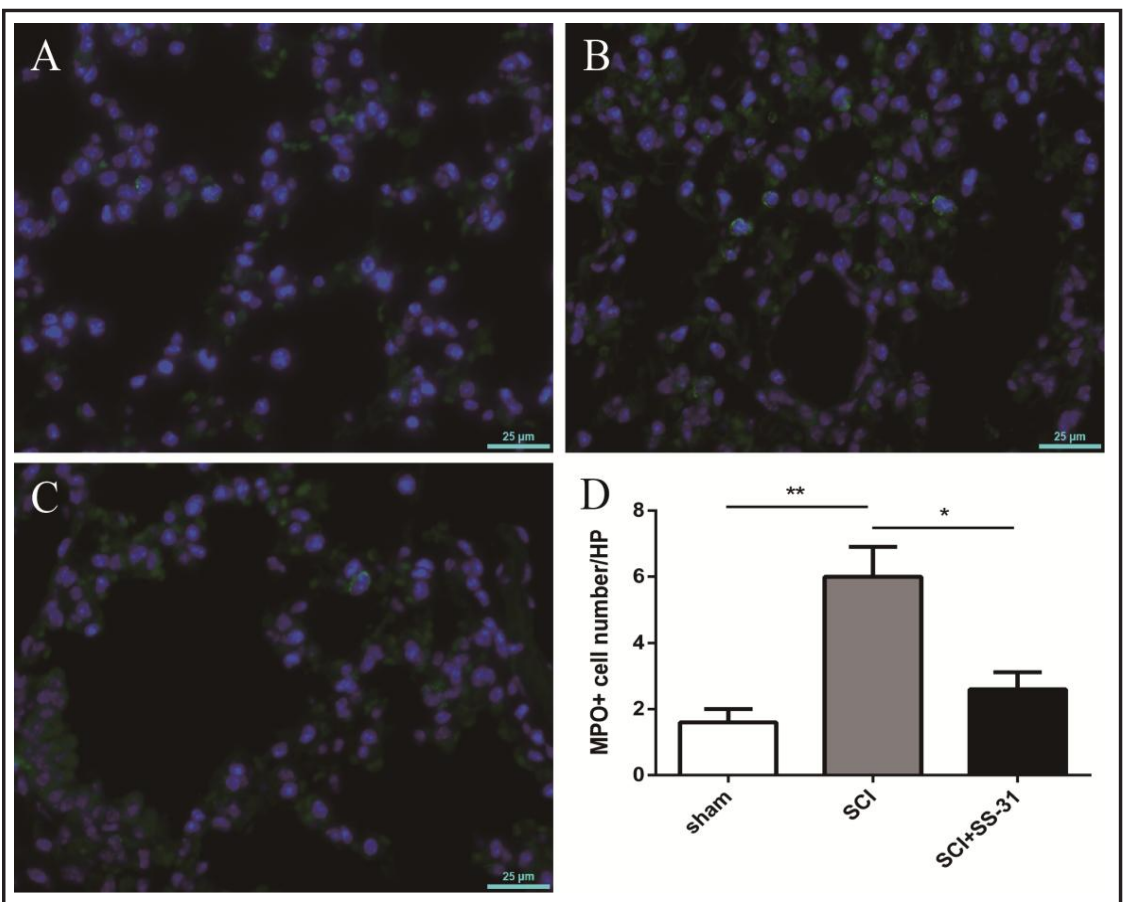

inflammatory cell infiltration, edema, hemorrhage, and congestion were seen in the SCI group. Moreover, the SCI group ( $4.2 \pm 0.29, \mathrm{P}<0.001$, Fig. $2 \mathrm{D})$ had a significant increase in lung damage score compared to the sham group $(0.70 \pm 0.15$, Fig. 2D). However, SS-31 treatment dramatically ameliorated histologic deterioration and reduced the lung damage score $(1.7 \pm 0.26, \mathrm{P}<0.001$, Fig. $2 \mathrm{D})$, suggesting that SS-31 treatment significantly ameliorates histological lung injury after SCI.

\section{SS-31 attenuates apoptosis of alveolar type II cells}

To detect apoptosis of alveolar type II cells, co-staining of SP-C (the marker of alveolar type II cells, red fluorescence) and TUNEL (green fluorescence) were performed (Fig. 3A, 3B). The number of TUNEL-positive alveolar type II cells was increased in the SCI group $(34.3 \pm 2.56, \mathrm{P}<0.001$, Fig. $3 \mathrm{~A}, 3 \mathrm{~B})$ compared to the sham group $(3.5 \pm 0.43$, Fig. 3A, 3B), whereas SS-31 treatment clearly reduced TUNEL-positive alveolar type II cells $(12.0 \pm 1.37$, $\mathrm{P}<0.001$, Fig. 3A, 3B). These data clearly show that SS-31 treatment significantly attenuates apoptosis of alveolar type II cells.

\section{SS-31 reduces neutrophil infiltration}

Myeloperoxidase (MPO), which is involved in the catalysis and formation of ROS [24], represents the activation and infiltration of neutrophils [25]. Thus, neutrophil infiltration was analyzed by MPO activity in this study. SCI mice exhibited a significant increase in neutrophil infiltration as shown by an elevation in MPO-positive (green fluorescence) cells $(6.0 \pm 0.89, \mathrm{P}=0.002$, Fig. 4A-4D) compared to sham mice $(1.6 \pm 0.60$, Fig. 4A-4D). However, this rise in MPO-positive cells after SCI was markedly attenuated by SS-31 treatment $2.6 \pm$ $0.51, P=0.11$, Fig. 4C,4D), indicating that SS-31 treatment significantly suppresses neutrophil infiltration in lung tissue.

\section{SS-31 diminishes macrophages}

To analyze the number of macrophages, the number of Iba-1-positive cells was estimated by immunofluorescence labeling [26]. Iba-1-positive (green fluorescence) cells were robustly elevated in the SCI group $(16.3 \pm 1.50$, $\mathrm{P}<0.001$, Fig. $5 \mathrm{~A}-5 \mathrm{D})$ compared to the

\section{KARGER}




\section{Cellular Physiology

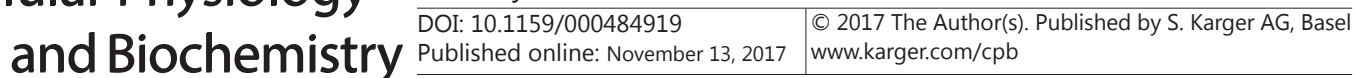

Fig. 5. SS-31 reduces the number of macrophages. (A,B) Immunofluorescence labeling was used to estimate the number of macrophages 3 days after SCI. (A) Sham, (B) SCI, (C) SCI+SS-31. (D) Quantification analysis of Iba1positive (green fluorescence) cells. HP, High power. $* * * \mathrm{P}<0.001$. Data represent means \pm SEM, $n=5$. Scale bars are $25 \mu \mathrm{m}$.
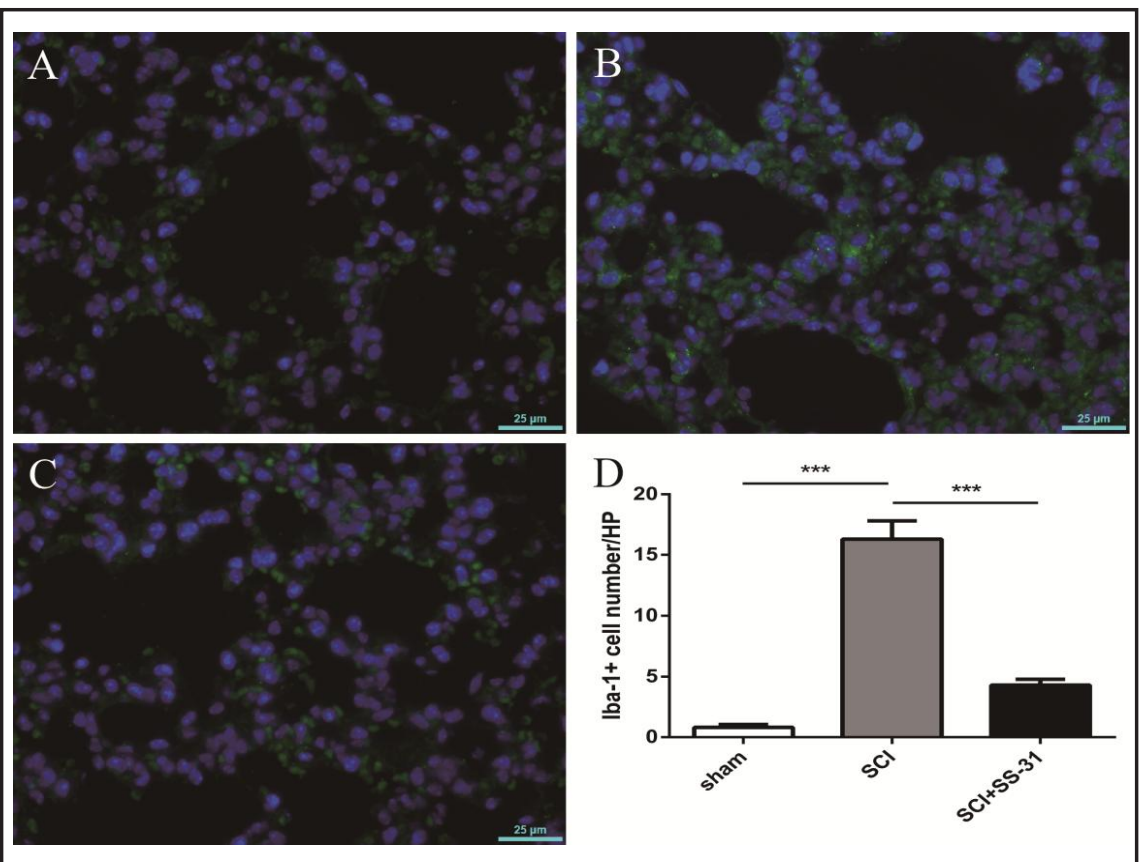

sham group ( $0.8 \pm 0.25$, Fig. $5 \mathrm{~A}-5 \mathrm{D})$, but this increase was alleviated by SS-31 treatment ( $4.3 \pm 0.50, \mathrm{P}<0.001$, Fig. $5 \mathrm{~A}-5 \mathrm{D})$, suggesting that SS-31 treatment significantly diminishes the number of macrophages.

\section{SS-31 decreases $M 1$ macrophages}

To quantitatively analyze M1 macrophages, we performed double-labeling immunofluorescence using antibodies against iNOS (a marker of M1 macrophages) [27] and CD68 (a marker of activated macrophages) [28]. As shown in Fig. 6A and 6B, the SCI group $(7.2 \pm 1.16, \mathrm{P}=0.001$ ) had a significant increase in the number of CD68 (green fluorescence)/ iNOS (red fluorescence) positive cells compared to the sham group (1.0 \pm 0.45$)$. This increase was markedly attenuated by SS-31 treatment $(1.8 \pm 0.58, \mathrm{P}=0.003$, Fig. $6 \mathrm{~A}, 6 \mathrm{~B})$.

We also determined the effects of SS-31 on mRNA expression of iNOS (Fig. 6C). SCI markedly increased iNOS mRNA expression in the SCI group $(1.9 \pm 0.15, \mathrm{P}=0.03$, Fig. $6 \mathrm{C})$ compared to the sham group $(1.0 \pm 0.16, \mathrm{P}=0.02$, Fig. $6 \mathrm{C})$, whereas up-regulation was alleviated by SS-31 treatment $(1.1 \pm 0.11, \mathrm{P}=0.02$, Fig. $6 \mathrm{C})$. These data clearly demonstrate that SS-31 treatment significantly decreases the number of M1 macrophages.

\section{SS-31 inhibits NLRP3 inflammasome activation}

NLRP3 inflammasome can promote caspase-1-dependent processing of the maturation and release of pro-inflammatory cytokine IL-1 $\beta$. NLRP3 $(0.4 \pm 0.04, \mathrm{P}=0.001$, Fig. 7A, 7B), active-caspase- $1(0.5 \pm 0.06, \mathrm{P}<0.001$, Fig. $7 \mathrm{~A}, 7 \mathrm{~B})$, and $\mathrm{IL}-1 \beta(0.2 \pm 0.03, \mathrm{P}=0.002$, Figures 7A, 7B) levels were significantly increased in SCI mice compared to sham mice (NLRP3: 0.13 \pm 0.03 ; active-caspase-1: $0.1 \pm 0.02$; IL-1 $8: 0.1 \pm 0.01$ ). However, treatment with SS-31 alleviated the up-regulation of NLRP3 $(0.20 \pm 0.13, P=0.001$, Fig. 7A, 7B), active-caspase- $1(0.2 \pm$ $0.03, \mathrm{P}=0.003$, Fig. $7 \mathrm{~A}, 7 \mathrm{~B})$, and IL-1 $\beta(0.1 \pm 0.02, \mathrm{P}=0.16$, Fig. $7 \mathrm{~A}, 7 \mathrm{~B})$, illustrating that SS-31 treatment significantly inhibits NLRP3 inflammasome activation.

\section{SS-31 inhibits mitochondrial dysfunction}

Based on a previous study [12], we investigated the effects of SS-31 on the change in mtDNA copy number, ATP synthases, and the release of cytosolic Cyt C three days post-injury to analyze mitochondrial dysfunction. SCI induced significant abnormalities in mitochondrial function, as shown by the reduction in mtDNA copy number $(1.0 \pm 0.12, \mathrm{P}=0.007$, Fig. $8 \mathrm{~A})$, 
Fig. 6. SS- 31 decreases the number of M1 macrophages. (A) Double-labeling immunofluorescence was used to estimate the number of M1 macrophages 3 days after SCI. (B) Quantification analysis of CD68 (green fluorescence)/iNOS (red fluorescence) positive cells. (C) Quantification analysis of iNOS mRNA 3 days after SCI. HP, High power. ${ }^{* *} \mathrm{P}<0.01$. Data represent means \pm SEM, $\mathrm{n}=5$. Scale bars are $25 \mu \mathrm{m}$.

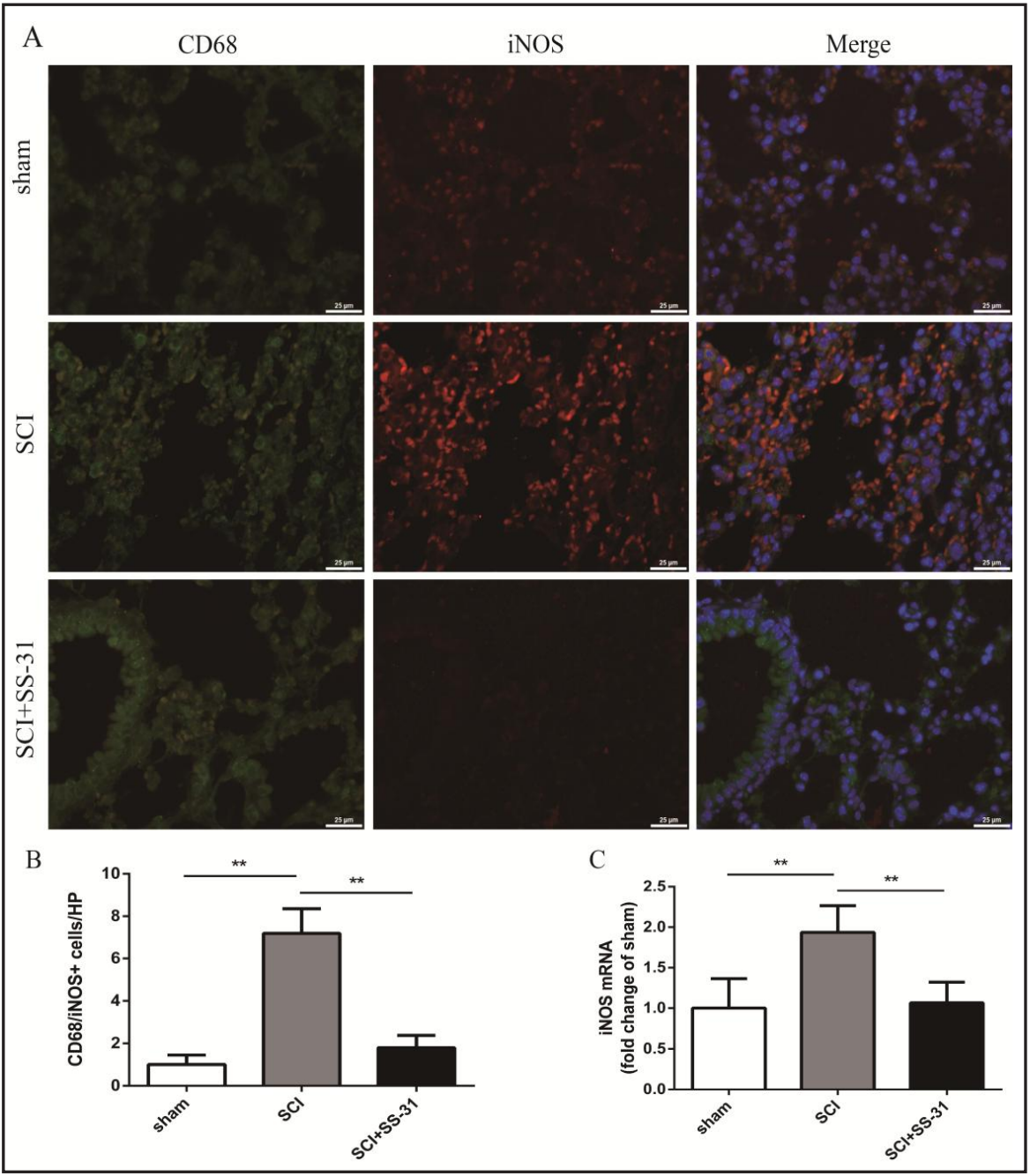

Fig. 7. SS-31 inhibits NLRP3 inflammasome activation. (A) Representative western blots of NLRP3, pro-caspase-1, active-caspase- 1 , pro-IL-1 $\beta$ and IL$1 \beta 3$ days postinjury. (B) Quantification analysis of NLRP3, active-
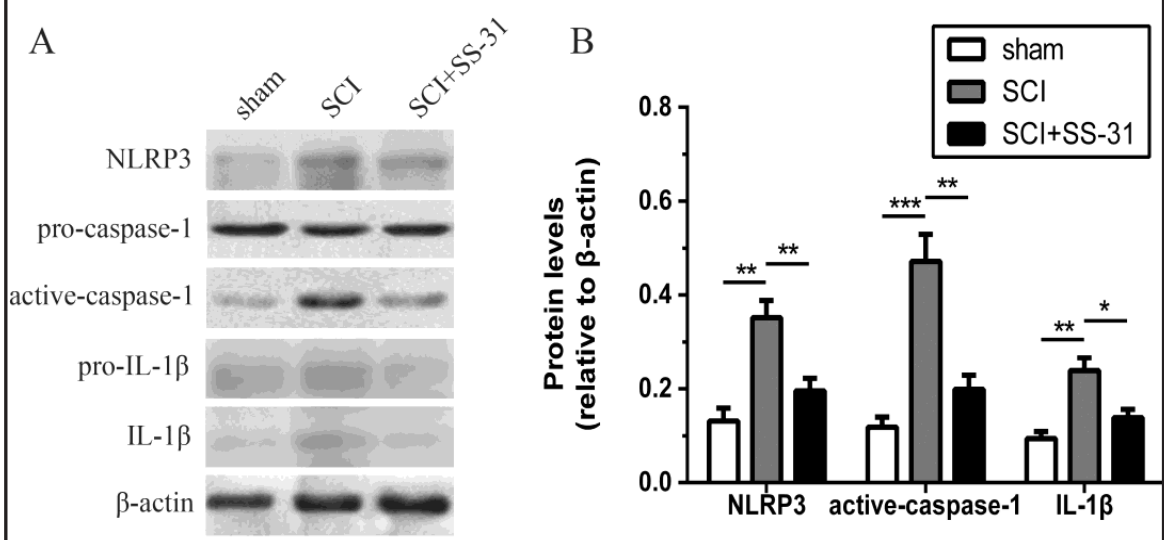
caspase- 1 and IL$1 \beta 3$ days post-injury. ${ }^{*} \mathrm{P}<0.05,{ }^{* *} \mathrm{P}<0.01,{ }^{* * *} \mathrm{P}<0.001$. Data represent means $\pm \mathrm{SEM}, \mathrm{n}=5$.

ATP synthases $(1.0 \pm 0.14, \mathrm{P}=0.007$, Fig. $8 \mathrm{~B})$ and release of Cyt $\mathrm{C}(0.6 \pm 0.04, \mathrm{P}<0.001$, Figures $8 \mathrm{C}, 8 \mathrm{D}$ ), in the SCI group compared to the sham group (mtDNA copy number: 0.5 \pm 0.08 ; ATP synthases: $0.4 \pm 0.08$; release of Cyt C: $0.3 \pm 0.03$, Figures $8 \mathrm{~A}-8 \mathrm{D}$ ). However, these abnormalities in mtDNA copy number $(0.9 \pm 0.09, \mathrm{P}=0.013$, Fig. $8 \mathrm{~A})$, ATP synthases

\section{KARGER}


A

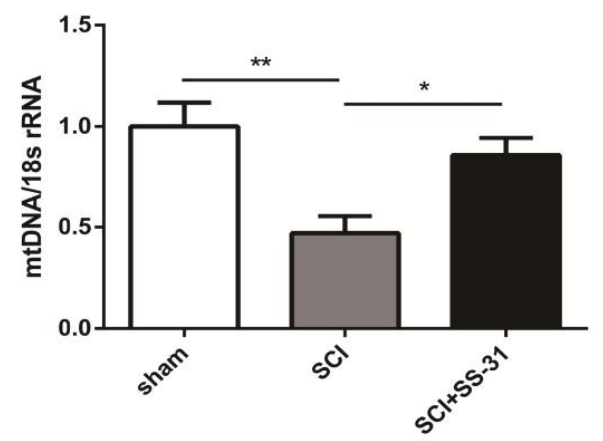

$\mathrm{B}$

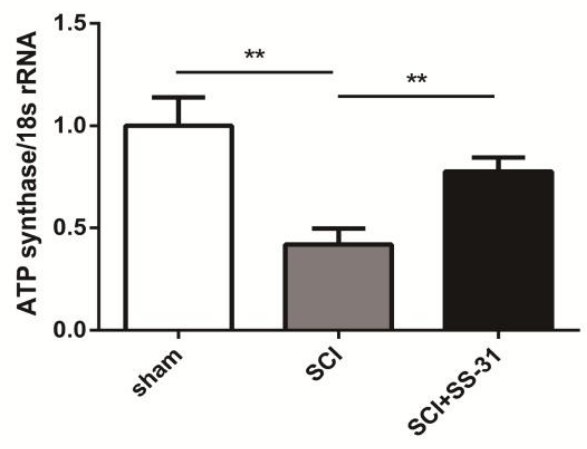

C

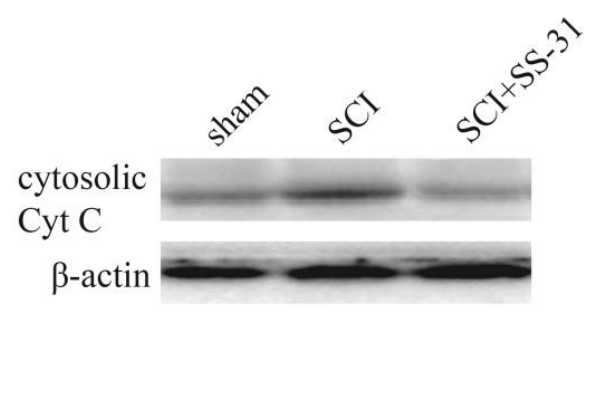

$\mathrm{D}$

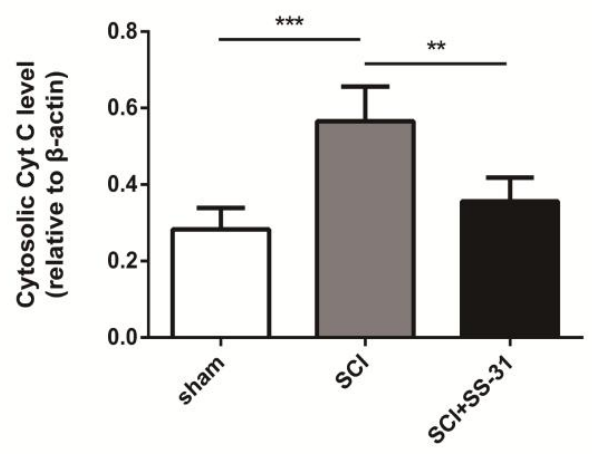

Fig. 8. SS-31 alleviates mitochondrial dysfunction. $(A, B)$ Real-time quantitative PCR analysis of ATP synthase and mitochondrial (mt)DNA 3 days post-injury. (C,D) Representative western blots and quantification analysis of cytosolic cytochrome c (Cyt C) 3 days post-injury. ${ }^{*} \mathrm{P}<0.05$, ${ }^{* *} \mathrm{P}<0.01,{ }^{* * *} \mathrm{P}<0.001$. Data represent means \pm SEM, $n=5$.

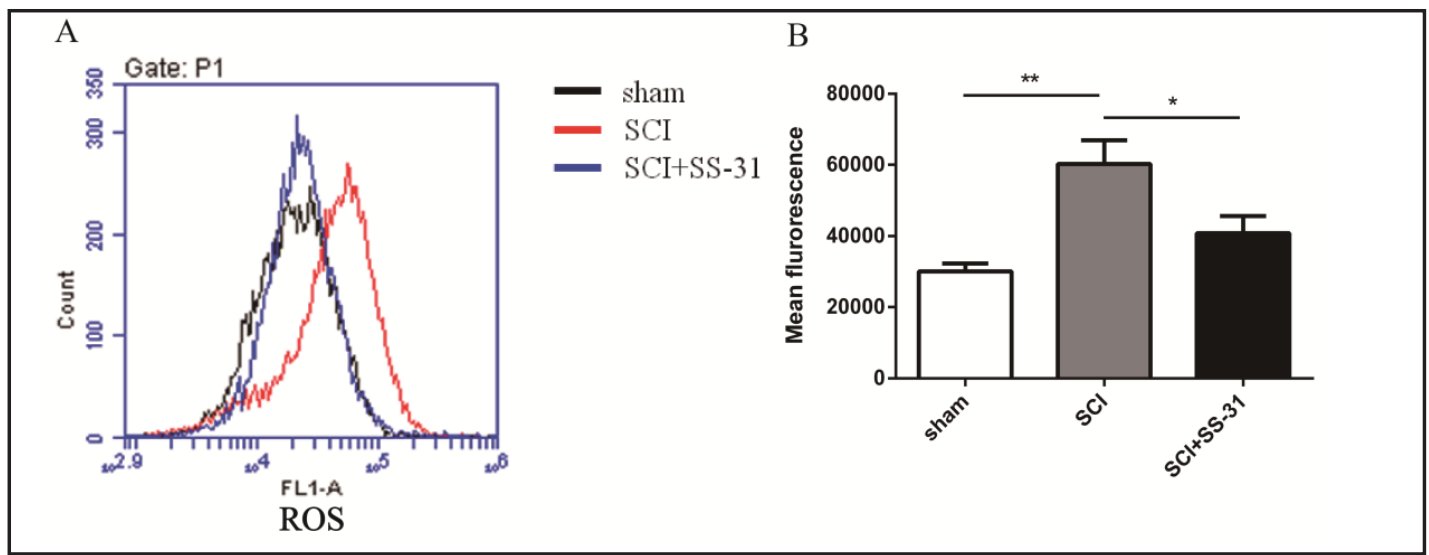

Fig. 9. SS-31 attenuates reactive oxygen species (ROS) level. (A,B) Representative flow cytometry and quantification analysis of ROS 3 days post-injury. ${ }^{*} \mathrm{P}<0.05$, ${ }^{* *} \mathrm{P}<0.01$. Data represent means $\pm \mathrm{SEM}, \mathrm{n}=5$.

$(0.8 \pm 0.07, P=0.009$, Fig. $8 \mathrm{~B})$ and release of Cyt $\mathrm{C}(0.4 \pm 0.03, \mathrm{P}=0.003$, Figures $8 \mathrm{C}, 8 \mathrm{D})$ were attenuated by SS-31 treatment. These data indicate that SS-31 treatment attenuates mitochondrial dysfunction.

\section{KARGER}




\section{Cellular Physiology Cell Physiol Biochem 2017;44:388-400 and Biochemistry Published online: November 13, 2017 \begin{tabular}{l|l} 
DOI: 10.1159/000484919 2017 The Author(s). Published by S. Karger AG, Basel \\
www.karger.com/cpb
\end{tabular} \\ Zhu et al.: SS-31 Attenuates Lung Injury}

SS-31 reduces ROS production

ROS production was also detected in lung tissue using flow cytometry. SCI mice (60229.1 \pm 6686.13 , P=0.003, Fig. 9A, 9B) showed a significant increase in ROS compared to sham mice (30010.7 \pm 2249.88 , Fig. 9A, 9B). However, this up-regulation was alleviated by SS-31 treatment (40818.9 $\pm 4817.15, \mathrm{P}=0.046$, Fig. 9A,9B). These data suggest that $\mathrm{SS}-31$ treatment significantly reduces ROS production.

\section{Discussion}

Recently, the mitochondrial targeted peptide SS-31 has been shown to have protective effects in many disease models [29-31]. SS-31 ameliorates isoflurane-induced impairments of mitochondrial morphogenesis and cognition deficits in rats [29]. Furthermore, SS-31 attenuates renal injury in diabetic nephropathy through an antioxidant effect [30]. Moreover, SS-31 alleviates pulmonary arterial hypertension induced by transverse aortic constriction in mice [31]. However, the effects of SS-31 on SCI-induced lung injury are unclear. Here, our results clearly demonstrated that SS-31 attenuated mitochondrial dysfunction, controlled inflammatory responses and alleviated the severity of lung damage in a mouse model of SCIinduced lung injury.

Mitochondria are important intracellular organelles in controlling cellular energy metabolism [32]. Moreover, mitochondria are a major source of reactive oxygen species (ROS) and contribute to cell signal transduction [12]. Mitochondrial dysfunction leads to an increase in ROS production, mitochondrial DNA damage (copy number reduction and mutation), disorders in oxidative phosphorylation of the mitochondrial respiratory chain, and the reduction of ATP production [33]. Mitochondrial dysfunction is closely associated with lung injury $[15,16]$. Regulation of mitochondrial dysfunction attenuates lung tissue damage $[13,14]$. In the present study, we analyzed microglia polarization using mtDNA copy number, ATP synthases, and the release of cytosolic Cyt $C$ based on a previous study [12, 33]. We demonstrated that SS-31 attenuated the reduction of mtDNA copy number and ATP synthases, and the release of Cyt C. These results indicated that SS-31 treatment notably attenuates mitochondrial dysfunction in lung tissue after SCI.

There is increasing evidence to suggest that mitochondrial dysfunction contributes to NLRP3 inflammasome activation [12]. NLRP3 inflammasome is assembled by NLRP3, apoptosis-associated speck-like protein containing a caspase recruitment domain (ASC), caspase-1 released after an endogenous "danger signal" and exogenous infection, comprise an important cytosolic protein complex [34]; this provides a caspase-1-activation platform to promote the maturation and release of proinflammatory cytokines, including IL-1 $\beta$ and IL-18 [35]. NLRP3 inflammasome plays a critical role in lung injury in diverse models [34, 36]. Inhibition of NLRP3 inflammasome activation attenuated lung tissue damage and the pulmonary inflammatory response in a mouse model of LPS-induced lung injury [36]. Inhibition of NLRP3 inflammasome also attenuated ventilation-induced lung injury [34]. In this study, we found that SS-31 reduced the expression of NLRP3, active-caspase-1, and IL-1 $\beta$. These results suggest that SS-31 treatment markedly inhibits NLRP3 inflammasome activation in lung tissue following SCI in mice.

Neutrophils and macrophages assemble in the lung tissue and participate in SCI-induced pulmonary events $[4,6]$. Moreover, neutrophils are believed to be the crucial inflammatory cells that migrate from the circulation to the lung parenchyma $[4,6]$. Neutrophils, which secrete elastase, proteases, and MPO, can result in lung tissue damage [37]. Targeting neutrophils prevented malaria-associated lung injury in mice [38]. Our data show that SS-31 reduced MPO-positive cells, suggesting that SS-31 treatment suppresses neutrophil invasion to lung tissue following SCI.

Macrophage differentiation is divided into the M1 and M2 phenotypes and different subsets exert distinct features [39, 40]. M1 macrophages are associated with high levels of proinflammatory cytokines and have detrimental effects and toxicity [41]; whereas, M2 


\section{Cellular Physiology Cell Physiol Biochem 2017;44:388-400 \begin{tabular}{l|l|l|}
\hline and BOI: 10.1159/000484919 & $\begin{array}{l}\text { C) } 2017 \text { The Author(s). Published by S. Karger AG, Basel } \\
\text { www.karger.com/cpb }\end{array}$ \\
\hline
\end{tabular} \\ Zhu et al.: SS-31 Attenuates Lung Injury}

macrophages produce anti-inflammatory mediators and exhibit regeneration and protection [40]. The reduction of M1 macrophages alleviates damaging inflammatory activity in the lung [41]. Here, we demonstrated that SS-31 decreased Iba1-positive cells and CD68/iNOSpositive cells. In addition, SS-31 also decreased iNOS mRNA. These results indicate that SS31 reduces the number of total macrophages and M1 macrophages.

\section{Conclusion}

Collectively, our results demonstrate that SS-31 attenuates mitochondrial dysfunction, controls inflammatory responses, and alleviates the severity of lung damage in a mouse model of SCI-induced lung injury.

\section{Acknowledgements}

This study was supported by the National Nature Science Foundation of China (grant no. 81702163) and the Traditional Chinese Medicine Science and Technology Project of Zhejiang (grant no.2011ZA078).

\section{Disclosure Statement}

The authors declare that they have no Disclosure Statement.

\section{References}

1 Paterniti I, Impellizzeri D, Di Paola R, Esposito E, Gladman S, Yip P, Priestley JV, Michael-Titus AT, Cuzzocrea $\mathrm{S}$ : Docosahexaenoic acid attenuates the early inflammatory response following spinal cord injury in mice: in-vivo and in-vitro studies. J Neuroinflammation 2014;11:6.

-2 Galeiras Vázquez R, Rascado Sedes P, Mourelo Fariña M, Montoto Marqués A, Ferreiro Velasco ME: Respiratory management in the patient with spinal cord injury. Biomed Res Int 2013;2013:168757.

-3 Tiftik T, Gökkaya NK, Malas FÜ, Tunç H, Yalçın S, Ekiz T, Erden E, Akkuş S: Does locomotor training improve pulmonary function in patients with spinal cord injury? Spinal Cord 2015;53:467-470.

4 Bao F, Brown A, Dekaban GA, Omana V, Weaver LC: CD11d integrin blockade reduces the systemic inflammatory response syndrome after spinal cord injury. Exp Neurol 2011;231:272-283.

5 Sun X, Jones ZB, Chen XM, Zhou L, So KF, Ren Y: Multiple organ dysfunction and systemic inflammation after spinal cord injury: a complex relationship. J Neuroinflammation 2016;13:260.

6 Bao F, Omana V, Brown A, Weaver LC: The systemic inflammatory response after spinal cord injury in the rat is decreased by $\alpha 4 \beta 1$ integrin blockade. J Neurotrauma 2012;29:1626-1637.

7 Jiang W, Li M, He F, Yao W, Bian Z, Wang X, Zhu L: Protective Effects of Asiatic Acid Against Spinal Cord Injury-Induced Acute Lung Injury in Rats. Inflammation 2016;39:1853-1861.

-8 Gris D, Hamilton EF, Weaver LC: The systemic inflammatory response after spinal cord injury damages lungs and kidneys. Exp Neurol 2008;211:259-270.

-9 He B, Nan G: Pulmonary edema and hemorrhage after acute spinal cord injury in rats. Spine J 2016;16:547551.

10 Yong T, Lili Y, Wen Y, Xinwei W, Xuhui Z: Pulmonary edema and hemorrhage, possible causes of pulmonary infection and respiratory failure in the early stage of lower spinal cord injury. Med Hypotheses 2012;79:299-301.

11 Li L, Chen Y, Gibson SB: Starvation-induced autophagy is regulated by mitochondrial reactive oxygen species leading to AMPK activation. Cell Signal 2013;25:50-65.

-12 Zhuang Y, Yasinta M, Hu C, Zhao M, Ding G, Bai M, Yang L, Ni J, Wang R, Jia Z, Huang S, Zhang A: Mitochondrial dysfunction confers albumin-induced NLRP3 inflammasome activation and renal tubular injury. Am J Physiol Renal Physiol 2015;308:F857-866. 


\section{Cellular Physiology Cell Physiol Biochem 2017;44:388-400 \begin{tabular}{l|l|l} 
DOI: 10.1159/000484919 & $\begin{array}{l}\text { O 2017 The Author(s). Published by S. Karger AG, Basel } \\
\text { www.karger.com/cpb }\end{array}$
\end{tabular} \\ Zhu et al.: SS-31 Attenuates Lung Injury}

13 Zhang ZY, Fan ZK, Cao Y, Jia ZQ, Li G, Zhi XD, Yu DS, Lv G: Acetyl-L- carnitine ameliorates mitochondrial damage and apoptosis following spinal cord injury in rats. Neurosci Lett 2015;604:18-23.

14 Du Q, Wang C, Zhang N, Li G, Zhang M, Li L, Zhang Q, Zhang J: In vivo study of the effects of exogenous hydrogen sulfide on lung mitochondria in acute lung injury in rats. BMC Anesthesiol 2014;14:117.

15 Zhang L, Deng S, Zhao S, Ai Y, Zhang L, Pan P, Su X, Tan H, Wu D: Intra-Peritoneal Administration of Mitochondrial DNA Provokes Acute Lung Injury and Systemic Inflammation via Toll-Like Receptor 9. Int J Mol Sci 2016;17.pII:E1425.

16 Lee YL, Obiako B, Gorodnya OM, Ruchko MV, Kuck JL, Pastukh VM, Wilson GL, Simmons JD, Gillespie MN: Mitochondrial DNA Damage Initiates Acute Lung Injury and Multi-Organ System Failure Evoked in Rats by Intra-Tracheal Pseudomonas Aeruginosa. Shock 2017;48:54-60.

-17 Siegel MP, Kruse SE, Percival JM, Goh J, White CC, Hopkins HC, Kavanagh TJ, Szeto HH, Rabinovitch PS, Marcinek DJ: Mitochondrial-targeted peptide rapidly improves mitochondrial energetics and skeletal muscle performance in aged mice. Aging Cell 2013;12:763-771.

18 Sweetwyne MT, Pippin JW, Eng DG, Hudkins KL, Chiao YA, Campbell MD, Marcinek DJ, Alpers CE, Szeto HH, Rabinovitch PS, Shankland SJ: The mitochondrial-targeted peptide, SS-31, improves glomerular architecture in mice of advanced age. Kidney Int 2017;91:1126-1145.

19 Wu J, Zhang M, Hao S, Jia M, Ji M, Qiu L, Sun X, Yang J, Li K: Mitochondria-Targeted Peptide Reverses Mitochondrial Dysfunction and Cognitive Deficits in Sepsis-Associated Encephalopathy. Mol Neurobiol 2015;52:783-791.

20 Paterniti I, Impellizzeri D, Di Paola R, Esposito E, Gladman S, Yip P, Priestley JV, Michael-Titus AT, Cuzzocrea S: Docosahexaenoic acid attenuates the early inflammatory response following spinal cord injury in mice: in-vivo and in-vitro studies. J Neuroinflammation 2014;11:6.

-21 Zhang D, Xuan J, Zheng BB, Zhou YL, Lin Y, Wu YS, Zhou YF, Huang YX, Wang Q Shen LY, Mao C, Wu Y, Wang XY, Tian NF, Xu HZ, Zhang XL: Metformin Improves Functional Recovery After Spinal Cord Injury via Autophagy Flux Stimulation. Mol Neurobiol 2017;54:3327-3341.

22 Li G, Wu J, Li R, Yuan D, Fan Y, Yang J, Ji M, Zhu S: Protective Effects of Antioxidant Peptide SS-31 Against Multiple Organ Dysfunctions During Endotoxemia. Inflammation 2016;39:54-64.

-23 Zhang Y, Li X, Grailer JJ, Wang N, Wang M, Yao J, Zhong R, Gao GF, Ward PA, Tan DX, Li X: Melatonin alleviates acute lung injury through inhibiting the NLRP3 inflammasome. J Pineal Res 2016;60:405-414.

24 Shi LB, Tang PF, Zhang W, Zhao YP, Zhang LC, Zhang H: Naringenin inhibits spinal cord injury-induced activation of neutrophils through miR-223 Gene 2016;592:128-133.

25 Eiserich JP, Hristova M, Cross CE, Jones AD, Freeman BA, Halliwell B, van der Vliet A: Formation of nitric oxide-derived inflammatory oxidants by myeloperoxidase in neutrophils. Nature 1998;391:393-397.

26 Xu Y, Meng C, Liu G, Yang D, Fu L, Zhang M, Zhang Z, Xia H, Yao S, Zhang S: Classically Activated Macrophages Protect against Lipopolysaccharide-induced Acute Lung Injury by Expressing Amphiregulin in Mice. Anesthesiology 2016;124:1086-1099.

27 Li C, Ding XY, Xiang DM, Xu J, Huang XL, Hou FF, Zhou QG: Enhanced M1 and Impaired M2 Macrophage Polarization and Reduced Mitochondrial Biogenesis via Inhibition of AMP Kinase in Chronic Kidney Disease. Cell Physiol Biochem 2015;36:358-372.

-28 Peng W, Cotrina ML, Han X, Yu H, Bekar L, Blum L, Takano T, Tian GF, Goldman SA, Nedergaard M: Systemic administration of an antagonist of the ATP-sensitive receptor P2X7 improves recovery after spinal cord injury. Proc Natl Acad Sci U S A 2009;106:12489-12493.

29 Wu J, Hao S, Sun XR, Zhang H, Li H, Zhao H, Ji MH, Yang JJ, Li K: Elamipretide (SS-31) Ameliorates Isoflurane-Induced Long-Term Impairments of Mitochondrial Morphogenesis and Cognition in Developing Rats. Front Cell Neurosci 2017;11:119.

-30 Hou Y, Li S, Wu M, Wei J, Ren Y, Du C, Wu H, Han C, Duan H, Shi Y: Mitochondria-targeted peptide SS-31 attenuates renal injury via an antioxidant effect in diabetic nephropathy. Am J Physiol Renal Physiol 2016;310:F547-559.

-31 Pang Y, Wang C, Yu L: Mitochondria-Targeted Antioxidant SS-31 is a Potential Novel Ophthalmic Medication for Neuroprotection in Glaucoma. Med Hypothesis Discov Innov Ophthalmol 2015;4:120-126.

-32 Zhang M, Pan H, Xu Y, Wang X, Qiu Z, Jiang L: Allicin Decreases Lipopolysaccharide- Induced Oxidative Stress and Inflammation in Human Umbilical Vein Endothelial Cells through Suppression of Mitochondrial Dysfunction and Activation of Nrf2. Cell Physiol Biochem 2017;41:2255-2267. 


\section{Cellular Physiology Cell Physiol Biochem 2017;44:388-400 \begin{tabular}{l|l} 
DOI: 10.1159/000484919 & $\begin{array}{l}\text { O 2017 The Author(s). Published by S. Karger AG, Basel } \\
\text { www.karger.com/cpb }\end{array}$
\end{tabular} \\ Zhu et al.: SS-31 Attenuates Lung Injury}

-33 Zhuang Y, Yasinta M, Hu C, Zhao M, Ding G, Bai M, Yang L, Ni J, Wang R, Jia Z, Huang S, Zhang A: Mitochondrial dysfunction confers albumin-induced NLRP3 inflammasome activation and renal tubular injury. Am J Physiol Renal Physiol 2015;308:F857-866.

34 Wang Y, Xu CF, Liu YJ, Mao YF, Lv Z, Li SY, Zhu XY, Jiang L:Salidroside Attenuates Ventilation Induced Lung Injury via SIRT1-Dependent Inhibition of NLRP3 Inflammasome. Cell Physiol Biochem 2017;42:34-43.

-35 Wang Y, Han Z, Fan Y, Zhang J, Chen K, Gao L, Zeng H, Cao J, Wang C: MicroRNA-9 Inhibits NLRP3 Inflammasome Activation in Human Atherosclerosis Inflammation Cell Models through the JAK1/STAT Signaling Pathway. Cell Physiol Biochem 2017;41:1555- 1571.

-36 Liu T, Zhou Y, Li P, Duan JX, Liu YP, Sun GY, Wan L, Dong L, Fang X, Jiang JX, Guan CX: Blocking triggering receptor expressed on myeloid cells-1 attenuates lipopolysaccharide- induced acute lung injury via inhibiting NLRP3 inflammasome activation. Sci Rep 2016;6:39473.

37 Zhou X, Dai Q, Huang X:Neutrophils in acute lung injury. Front Biosci (Landmark Ed) 2012;17:2278-2283.

-38 Sercundes MK, Ortolan LS, Debone D, Soeiro-Pereira PV, Gomes E, Aitken EH, Neto AC, Russo M, D’ Império Lima MR, Alvarez JM, Portugal S, Marinho CR, Epiphanio S:Targeting Neutrophils to Prevent Malaria-Associated Acute Lung Injury/Acute Respiratory Distress Syndrome in Mice. PLoS Pathog 2016;12:e1006054.

39 Li F, Zhu X, Yang Y, Huang L, Xu J:TIPE2 Alleviates Systemic Lupus Erythematosus Through Regulating Macrophage Polarization. Cell Physiol Biochem 2016;38:330-339.

40 Chiu CW, Huang WH, Lin SJ, Tsai MJ, Ma H, Hsieh SL,Cheng H: The immunomodulator decoy receptor 3 improves locomotor functional recovery after spinal cord injury. J Neuroinflammation 2016;13:154.

-41 Ying H, Kang Y, Zhang H, Zhao D, Xia J, Lu Z,Wang H, Xu F, Shi L: MiR-127 modulates macrophage polarization and promotes lung inflammation and injury by activating the JNK pathway. J Immunol 2015;194:1239-1251. 